\title{
Blockchain-enabled circular supply chain management: A system architecture for fast fashion
}

\author{
Bill Wang ${ }^{a}$, Wen Luo ${ }^{b}$, Abraham Zhang ${ }^{a, c}$, Zonggui Tian ${ }^{d}$, Z. Li $^{\text {d,* }}$ \\ a Auckland University of Technology (AUT) Business School, AUT University, Private Bag \\ 92006, Auckland, 1142, New Zealand \\ b Centre for Business and Enterprise, Waikato Institute of Technology, Hamilton, New \\ Zealand \\ ${ }^{\mathrm{C}}$ Lumen Research Institute, Excelsia College and Indiana Wesleyan University, 69-71 \\ Waterloo Road, Macquarie Park, NSW, 2113, Australia \\ d Guangdong Provincial Key Laboratory of Computer Integrated Manufacturing \\ Systems, School of Electromechanical Engineering, Guangdong University of \\ Technology, Guangzhou, Guangdong, 510oo6, China
}

\begin{abstract}
Circular supply chain management is required for firms to transition from a linear make-use-dispose eco- nomic model to a more sustainable circular economy. However, it faces the critical challenge of tracing the reuse of materials over multiple life cycles involving a variety of stakeholders. Blockchain technology can help manage the complexities of circular supply chain management. This paper takes the first step in developing a system architecture of blockchain-enabled circular supply chain management in the fast-fashion industry. The system architecture was validated by two experts in blockchain technology and supply chain management. Managerial implications are discussed for implementing blockchain technology to advance the circular economy agenda.
\end{abstract}

Keywords: Blockchain, Circular supply chain management Circular economy, Fast fashion 


\section{Introduction}

Industrial activities are a major cause of the global problems of environmental degradation and resource depletion/scarcity (Jackson, 2009; Sachs, 2015). The concept of circular economy (CE) has been developed over the past decade to help deal with these problems (Geissdoerfer et al., 2017). The definition of CE varies because each stakeholder has its own perspective and perception of it. For example, Kirchherr et al. (2017) developed an integrative concept of CE by synthesizing 114 relevant definitions, describing $\mathrm{CE}$ as:

An economic system that replaces the 'end-of-life' concept with reducing, alternatively reusing, recycling and recovering mate- rials in production/distribution and consumption processes. It operates at the micro-level (products, companies, consumers), meso-level (eco-industrial parks) and macro-level (city, region, nation and beyond), to accomplish sustainable development, thus simultaneously creating environmental quality, economic prosperity and social equity, to the benefit of current and future generations. It is enabled by novel business models and responsible consumers (p. 229).

CE differs from the traditional linear economic model (make- use-dispose) in two key aspects. Firstly, the linear model focuses on how to use resources efficiently, while CE focuses more on how to use them eco-effectively. Secondly, the linear model can only downcycle discarded items to make something with less value than the original. By contrast, $\mathrm{CE}$ focuses on upcycling discarded items to make something with a higher value (MacArthur, 2013; Sariatli, 2017). The regeneration and usage of waste can make the organization more competitive by enhancing resource efficiency, saving total costs, improving the organization's reputation, and minimizing environmental burdens (Ferreira et al., 2017; Masi et al., 2017; Zhu et al., 2017).

When all supply chain stakeholders work systematically to integrate the CE concept in the entire supply chain process, ideally, they can develop innovative business models and relevant supply chain functions to achieve zero-waste by upcycling all relevant resources, throughout the supply chain life cycle (Farooque et al., 2019b). This idea is called circular supply chain management (CSCM), and it is required for operationalizing $\mathrm{CE}$ at a micro-level. Implementing it brings the challenges of tracking how to upcycle materials over multiple life cycles across multiple supply chain stakeholders. The typical challenges are related to culture and society, government regulation and policy, technology, knowledge and skill, circular 
economic framework, and market (Govindan \& Hasanagic, 2018; Mangla et al., 2018; Ranta et al., 2018).

Many approaches have been tested and applied to deal with these challenges (Govindan \& Hasanagic, 2018). Among these approaches, Blockchain technology (BCT) has received particular attention for two reasons. Firstly, this technology has shown rapid growth in supporting supply chain traceability, sustainability, and information security over the last decade (Francisco \& Swanson, 2018; Saberi et al., 2019). Secondly, this technology can be used to cope with multiple CE challenges at the same time (Casado Vara et al., 2018; Kouhizadeh \& Sarkis, 2018; Kouhizadeh et al., 2019a, 2019b).

Some recent studies have developed frameworks to guide the implementation of BCT in assessing how the product life cycle can have better environmental performance (Liu et al., 2020; Zhang et al., 2020). However, there has been limited research on exploring the use of blockchain to enable CSCM in specific industries. While the life cycle assessment method is well established, CSCM is still an emerging concept which requires further investigation. Moreover, there is no study about how blockchain-enabled CSCM can impact managerial and policy decision-making to advance the development of CE. This research focuses on the fastfashion industry and has the following objectives:

- To develop a system architecture of blockchain-enabled CSCM in fast fashion

- To discuss theoretical and managerial implications of applying blockchain to advance CSCM

The ultimate target of CE and CSCM is zero waste (Farooque et al., 2019a). This research focuses on the fast-fashion industry because it is notorious for poor environmental sustainability (Joy et al., 2012). Therefore, this industry is an ideal field in which to investigate the development of blockchain-enabled CSCM. Although this is a pioneering conceptual work, the designed system architecture has been validated by two BCT and supply chain management (SCM) experts.

The remainder of the paper is organized as follows. Section 2 reviews the relevant literature on BCT and CSCM. Section 3 describes the sustainability challenges in the fast-fashion industry. 
Based on Sections 2 and 3, Section 4 presents a system architecture of blockchain-enabled CSCM. Section 5 discusses managerial and policy implications. Section 6 concludes the research.

\section{Literature review}

\subsection{Blockchain technology}

Nakamoto first proposed the concept of BCT in 2009. He defined this concept as a technology using data mining and bitcoin techniques to develop data structure and encode the transaction of information (Nakamoto, 2009). The information within a blockchain will be stored online permanently, with high transparency and security (Li et al., 2018). The key characteristics of BCT include decentralization, distrusting, transparency, traceable and unforgeable transactions, anonymity, and credibility ( $\mathrm{Lu}, 2019)$.

Lu (2018) argues that BCT may be applied in different platforms: "Blockchain technology is not limited to crypto currency and capital markets. It also conducts in-depth practice on smart contracts, net- work security and privacy, and other applications and platforms" (p. 238). Specifically, with the development of Internet of Things (IoT), the application of BCT can help organizations to develop collaborative services (Da Xu \& Viriyasitavat, 2019). In this situation, the architecture of service has also been updated because of BCT's fast development (Viriyasitavat et al., 2019).

Beyond facilitating traditional business and services, BCT has also supported the transition to a circular economy $(\mathrm{CE})$.

\subsection{Blockchain technology and circular economy}

Although the transition to CE is a trend for the fashion industry and supply chain, there are a number of barriers for this transition (Debacker et al., 2017)

1) Lack of standard policy

2) Higher complexity leads to resistance to changing the traditional linear economy and industry models 
3) Protection of intellectual property

4) High costs

5) Lack of quality assurance for recycled materials and re-used products

6) Most consumers have no idea about CE

Practitioners and academia have applied a number of approaches to deal with the barriers. BCT provides some practical support for CE transition. First of all, BCT can help to integrate and share information along the whole supply chain process. As a result, the exchange of materials and products can be smooth (Alexandris et al., 2018). Moreover, BCT offers higher security in relation to keeping and managing information online. This characteristic can prevent the leaking of confidential information and help to protect organizational intellectual property (Kouhizadeh et al., 2019a, 2019b). Finally, all supply chain members, especially consumers, can access more information quickly from the upstream, such as aspects relating to design, raw materials and manufacturing processes. BCT can facilitate consumer understanding of the whole supply chain and hence improve the integration and collaboration between supply chain members (Rusinek et al., 2018).

2.3. Blockchain technology for traditional supply chain

There are five common strategic objectives in traditional supply chain management. BCT can provide potential support to help to achieve these objectives effectively (Kshetri, 2018).

- Cost-BCT can generate a unique code for each transaction. It facilitates a comprehensive check of the financial flow within the whole supply chain process;

- Speed-BCT can increase process speed by minimizing physical interactions and communications;

- Risk control-With BCT, transactions can only occur when all related parties accept it in specific touchpoints within the BC net- work. This function helps to control the risk of data for all supply chain transactions;

- Sustainability-BCT can help to develop measurable and meaningful performance measurement indicators for environmental, economic, and social sustainability; 
- Flexibility_BCT can help the consumer to track and trace their orders and from upstream to downstream. This enables consumers to make changes easily and for suppliers to also adjust to the changes immediately.

Existing research on BCT applications in supply chain contexts can be roughly divided into four main categories: descriptive, conceptual, predictive, and prescriptive research (Wang et al., 2019). Table 1 summarizes some recent studies on BCT applications. Most of these studies are conceptual or based on a general supply chain context. For example, Treiblmaier (2018), Van Hoek (2019a), and Batwa \& Norrman (2020) use or develop frameworks/theories to study BCT from different perspectives. However, they do not investigate how to specifically apply BCT to solve SCM challenges in a particular industry. As recommended by Wang et al. (2019) and Queiroz et al. (2019), in comparison with current studies about drivers and potential outcomes of applying BCT in the supply chain context, it is also meaningful and critical to investigate how to apply BCT in SCM step by step for overcoming existing SCM challenges. Therefore, this study aims to address this gap by developing an architecture that illustrates the application of BCT in the fast- fashion supply chain, with a focus on enabling CSCM to improve the environmental sustainability of the industry.

Table 1: A summary of research studies on BCT in SCM

\begin{tabular}{|c|c|c|}
\hline Study & Focus & Industry \\
\hline $\begin{array}{l}\text { Apte and Petrovsky, } \\
2016\end{array}$ & Verification of material ingredients & Pharmaceutical \\
\hline Tian, 2017 & Model to apply BCT & Food \\
\hline Hull et al., 2017 & Implementing smart contract & General distribution \\
\hline Mansfield, 2017 & Fundamental concepts & Multiple \\
\hline Patel et al., 2017 & $\begin{array}{l}\text { Technical fundamentals, especially } \\
\text { digitalized transactions }\end{array}$ & Multiple \\
\hline Treiblmaier, 2018 & $\begin{array}{l}\text { Comparison of applying four different } \\
\text { theories in BCT study }\end{array}$ & General supply chain \\
\hline Cole et al., 2019 & Technology acceptance model & General supply chain \\
\hline Martinez et al., 2019 & $\begin{array}{l}\text { Combining BCT with Resource Based } \\
\text { View (RBV) and Information Processing } \\
\text { Theory (IPT) }\end{array}$ & $\begin{array}{l}\text { Heavy-assets equipment } \\
\text { manufacturing }\end{array}$ \\
\hline Saberi et al., 2019 & $\begin{array}{l}\text { General BCT adoption model and } \\
\text { barriers }\end{array}$ & Food \& Beverage \\
\hline van Hoek, 2019a & $\begin{array}{l}\text { Framework developed from BCT } \\
\text { implementation cases }\end{array}$ & Multiple \\
\hline van Hoek, 2019b & BCT implementation issues & Multiple \\
\hline van Hoek, 2019c & $\begin{array}{l}\text { Adapting RFID implementation } \\
\text { framework for BCT implementation }\end{array}$ & General supply chain \\
\hline $\begin{array}{l}\text { Batwa \& Norrman, } \\
2020\end{array}$ & Overall BCT case study framework & General supply chain \\
\hline
\end{tabular}


Before examining studies on BCT application in circular sup- ply chains in the fast-fashion industry, this paper provides context about the needs of the industry to move to a circular economy and how BCT is beneficial in this regard.

2.4. The fashion industry, circular economy, and blockchain technology

The fashion industry contributes more than $\$ 450$ billion in sales globally (Resta et al., 2016), making it one of the most significant industries across the world. However, it has also been shown to be the most harmful industry for the environment and has faced ongoing pressure to move to a more circular economic model (Koszewska, 2018).

From the initial stages of design through to manufacturing (Moorhouse \& Moorhouse, 2017; Bocken et al., 2018) and to the final service stages, CE ideas compel the fashion industry to prioritize sustainability in terms of focusing more on long-life products, using and reusing materials, and giving consideration to end-of-life products (Earley \& Goldsworthy, 2015). Concepts such as upcycling and recycling materials and products feature in the fashion industry's transition to $\mathrm{CE}$ and a major challenge concerns the alignment of values across the supply chain, particularly with those of the consumer (Todeschini et al., 2017).

As consumers become increasingly concerned with issues of sustainability, practices such as the upcycling or recycling of mate- rials grow in popularity. However, within the fashion industry, consumers are typically aware of what happens only at the retail stage and have limited information about how their purchasing decisions impact on other parties and parts of the supply chain. In being able to enhance the transparency of practices and processes across the supply chain, BCT is a practical means of increasing the alignment between consumer values and demand with the interests of other parties in the supply chain, prompting a move to a CE model (Vehmas et al., 2018).

Table 2: Focus of applying BCT to developing sustainability in fast-fashion industry

\begin{tabular}{|l|l|}
\hline Research & Focus \\
\hline Fu et al., 2018 & Carbon emissions and related scheme \\
\hline $\begin{array}{l}\text { Elmessiry \& Elmessiry, 2018a; Sacha, } \\
2019\end{array}$ & $\begin{array}{l}\text { Intellectual property, infringement, legal } \\
\text { regulations }\end{array}$ \\
\hline $\begin{array}{l}\text { Elmessiry \& Elmessiry, 2018b; Nyman, } \\
2019\end{array}$ & $\begin{array}{l}\text { Transparency, and prevention of unethical } \\
\text { actions }\end{array}$ \\
\hline
\end{tabular}


Several studies (summarized in Table 2 below) have investigated the application of BCT in the fashion industry from the CE perspective. However, none of these studies include architecture that shows the application of BCT from upstream to downstream.

The existing studies on BCT, CE, and the fashion industry have not combined all three dimensions in their examinations, which this paper sets out to do. This paper shows a connection between BCT, fast-fashion industry, and circular supply chain management (CSCM) - a brand new concept which views SCM from a CE perspective. The next two sections review the concept of CSCM and the application of BCT in CSCM, which provide the principles guiding this study.

\subsection{Blockchain technology for circular supply chain management}

The traditional sustainable supply chain management (SSCM) concept focuses on minimizing waste, but not the reuse and refurbishment of raw materials and waste. The concept of CSCM integrates circular thinking and the essence of CE into SCM (Farooque et al., 2019a). The goal of CSCM is to develop a zero- waste supply chain through all supply chain functions and within each stakeholder's realm (from the raw material suppliers to the final consumers) (Farooque et al., 2019b).

\subsubsection{Key areas of applying BCT in CSCM}

- Data Management Resource Deployment

Sound data management can help all stakeholders to make changes quickly (Kouhizadeh \& Sarkis, 2018). Blockchain can help CSCM by speeding up resource deployment, reducing waste and enhancing the resilience and flexibility of circular supply chains (Masi et al., 2017).

- Supplier selection and development

BCT can create platforms and databases by recording all suppliers' historical performance data. As a result, customers can quickly identify the most suitable suppliers (Saberi et al., 2019). In addition, BCT helps customers and suppliers to develop smart contracts to trace and benchmark supplier performance (Kouhizadeh \& Sarkis, 2018).

- Procurement 
BCT can track and analyse the life cycle of products, so all CSCM stakeholders can develop resource efficiency and material supply resilience simultaneously in the procurement process (Dobrovnik et al., 2018; Witjes \& Lozano, 2016).

- Production and operations

BCT can fully integrate the data of internal production and operations and that of external supply chain requirements. Therefore, all CSCM stakeholders can precisely align and audit their production and operations to satisfy the $3 \mathrm{R}$ rules of the CE concept (Kouhizadeh et al., 2019a, 2019b).

- Materials management in the logistics process

BCT makes products and materials highly traceable, minimizing the amount of products and materials lost through handling in the logistics process. As a result, the lead time can be shortened and resource efficiency improved in the logistics process (Dobrovnik et al., 2018).

- Reverse logistics

Characteristics of reverse logistics show close resemblance to recycling, recovering, and reusing materials, products, and waste. However, traditional reverse logistics suffers from difficulty in obtaining accurate information regarding the time, location, quality, and condition of the materials, products, and waste. The root cause is the complicated nature of the multi-tier supply chain processes (Kouhizadeh et al., 2019a, 2019b). BCT can track all trans- actions in a supply chain. Therefore, CSCM stakeholders can easily monitor and control the entire reverse logistics process to reuse and refurbish wastes and to return components (Kouhizadeh \& Sarkis, 2018).

- Supply chain control

Supply chain stakeholders can obtain better control of the efficiency of inventory, resource usage, and processes via the traceability and transparency of transactions in blockchain (Tseng et al., 2018). Moreover, information transparency can also minimize stakeholders' opportunistic behaviour (Lindström et al., 2018). Finally, data sharing in blockchain can facilitate supply chain collaboration (Saberi et al., 2019; Tian et al. 2020).

- Green product management 
Information about green products is difficult to obtain and man- age. BCT can be used to obtain and store data on green products. For example, BCT can monitor gas emissions, enabling customers to see whether a product is green or not (Rosencrance, 2017).

- Reusing waste across different circular supply chains

BCT can provide a platform to encourage the integration of the $\mathrm{CE}$ concept across different circular supply chains and all relevant stakeholders. For example, when two companies from different circular supply chains need each other's waste or used components, they can make transactions and free exchanges without any middleman. Thus, BCT can benefit multiple circular supply chains at the same time (Kouhizadeh et al., 2019a, 2019b).

\subsubsection{Barriers in applying BCT in CSCM}

However, the application of BCT in developing a sustainable supply chain is not without barriers (Saberi et al., 2019):

1) Intra-organizational barriers, such as resistance to change, lack of resources to apply BCT, lack of training to use BCT (Govindan \& Hasanagic, 2018; Pan et al., 2015; Sternberg \& Baruffaldi, 2018);

2) Inter-organizational barriers, such as conflict of interests, arm's- length business relationships, and lack of common interests and mutual trust (Lambert \& Enz, 2017);

3) Technical barriers, such as IT, software and hardware equipment issues and lack of alignment between the systems of different organizations (Abeyratne \& Monfared, 2016; Sternberg \& Baruffaldi, 2018; Farooque et al., 2020);

4) External barriers, including government regulations and policies, unique industry standards, etc. (Mangla et al., 2018; Saberi et al., 2019; Farooque et al., 2020)

Of the identified barriers, the technical barriers are the most challenging as BCT combines different components of the latest information technology (i.e., bitcoin, internet, cloud, etc.) (Saberi et al., 2019). This study, therefore, identifies some related technical barriers and potential solutions in addition to developing the architecture for BCT applications for CSCM in the fashion industry. It is, therefore, imperative to first understand the challenges of managing the fast-fashion supply chain from a CE perspective.

3. Sustainability challenges in the fast fashion 
This section describes the sustainability challenges in fast fashion to set the stage for the presentation, in the following section, of a blockchain-enabled CSCM system architecture.

\subsection{Product economics of fast-fashion products and supply chain}

Fast fashion refers to "low-cost clothing collections that mimic current luxury fashion trends" (Joy et al., 2012, p. 273). Thanks to the JIT (Just-in-time) manufacturing philosophy and Quick Response strategies, fast fashion only takes weeks to get from the product design stage to the market (Morgan \& Birtwistle, 2009), com- pared with six-month cycles in the traditional apparel model (Gabrielli et al., 2013). Because of streamlined operations (Remy \& Swartz, 2016) and reduction in costs by outsourcing manufacturing to lower-wage countries (Bhardwaj \& Fairhurst, 2010), the fast-fashion industry has transited from being product driven to being market driven (Bhardwaj \& Fairhurst, 2010) and has established demand-driven flexible SCM despite major physical distances across the chain. Consequently, fast fashion has burst into the apparel market by offering consumers, especially younger generations, a continually changing assortment of clothing (Gabrielli et al., 2013).

As fast fashion promotes a throwaway culture (Brooks, 2019), it has brought about changes in consumers' behaviour, such as impulse shopping (Ryu, 2011), the pursuit of emotional "highs" by constant purchasing, and emotionally addictive searching (Johnson \& Attmann, 2009). Fastfashion consumption has a certain appeal in combining the wearing and ownership of clothes (Iran \& Geiger, 2018). The attitudes and behaviour associated with fast fashion have created a correlative interaction with the fashion product life cycle. Baker- Brown (2017) states that 80 $\%$ of fashion products turn into "waste" and are thrown away within the first six months. All this leads to exponentially increasing production. According to Remy and Swartz (2016), clothing production doubled from 2000 to 2014, and the number of garments purchased each year by the average consumer increased by $60 \%$, with fast fashion contributing significantly to the industry's production. For example, fast fashion accounts for one-fifth of the total clothing market in the United Kingdom (Morgan \& Birtwistle, 2009).

\subsection{Environmental problems related to fast-fashion production}


Since fast fashion encourages disposability (Joy et al., 2012), leaves a carbon footprint with each step of the clothing life cycle, generates potential environmental and occupational hazards (Claudio, 2007), and emits significant amounts of greenhouse gases (Kant, 2011), it has huge environmental effects (Remy et al., 2016). For example, globally, $20 \%$ of industrial water pollution is caused by the dyeing, bleaching, washing, and treatment of textiles (Kant, 2011). Waste reaches 98 million tons in total per year-including oil to produce synthetic fibers; fertilizers to grow cotton; and chemicals to produce, dye, and finish fibers and textiles (Morlet et al., 2017; Turker \& Altuntas, 2014). Cotton crops account for a quarter of all the pesticides used in the United States (Claudio, 2007). Mean- while, fashion products use an immense number of accessories and packaging, including labels, tags, and plastic/paper bags or containers. These resources are wasted quickly, as the product lifetime is very short (Niinimäki, 2018). In short, fashion is widely considered the second most destructive industry to the environment, after the oil industry (Moorhouse \& Moorhouse, 2017).

More importantly, as fast-fashion manufacturing has been outsourced to low-wage countries to reduce costs (Bhardwaj \& Fairhurst, 2010), related environmental issues have worsened. Firstly, the price of resources such as clean water, energy, and land is so low that it is easily ignored or subsidized by the local government (Niinimäki, 2018). Secondly, most low-wage countries lack concern for environmental quality (Dunlap, 2012) and have lower environmental standards (Muradian \& Martinez-Alier, 2001). This plays into the hands of fast-fashion manufacturing, which uses harmful and toxic chemicals and does not treat waste properly (Niinimäki, 2018). Finally, as the fast-fashion consumption market is far away from the manufacturing countries, the harmful environ- mental impacts at production sites are often not seen by the public at the consumption sites.

\subsection{The social problems related to fast-fashion production}

Many fast-fashion companies outsource garment manufacturing to low-wage countries where most of the employees work in poor conditions. Claudio (2007) reported some examples in Asia. In Phnom Penh, Cambodia, more than 2,000 young women can only afford to sleep on the floor of a garment factory that is producing clothes for shops in Europe and North America. In Dhaka, Bangladesh, child laborers work in textile factories for $10 \mathrm{~h}$ a day to earn US $\$ 1$ with the threat of corporal punishment hanging over their heads. In a jeans factory in China, thousands of workers labour around the clock, scrubbing, spraying, and tearing jeans in order 
to meet fashionable production demands even though the blue dust from the jeans is a heavy irritant to the lungs. Akhter (2014) claims that Bangladesh's garment workers are the most exploited, with the lowest minimum wage in the world, and that they are deprived of rights such as unionism and collective bargaining; female workers also often face mental and sexual harassment and work in dangerous situations. Fast-fashion workers can even face fatal risks during the manufacturing process. In 2013, at least 1,132 garment workers lost their lives and more than 2500 were injured from a factory building collapsing in Dhaka, Bangladesh (Taplin, 2014). Low-wage countries generally lack consistent government monitoring of garment factories for compliance with laws and regulations (Monte, 2000). Altogether, there exists a serious problem related to social responsibility in the fast-fashion industry in terms of poor working conditions, long working hours, child-labour, exploitative wages, human rights, etc.

Out of the economic, environmental, and social problem areas, the first is the biggest, as the other two stems from it. Given that the industry production technology and operations management mode cannot make disruptive change, the more production is carried out, the more the natural environment will be polluted, and the more the fashion industry workers will suffer risk and harm.

4. System architecture of blockchain-enabled circular supply chain management in fast fashion

Blockchain can be adopted in supply chain operations to make transactions safer and more transparent, traceable, and efficient (Queiroz \& Wamba, 2019). With increasing awareness of the need for sustainability in the fast-fashion industry, more and more producers and retailers, such as Zara and H\&M, have recently invested in sustainable actions (Todeschini et al., 2017), a trend that is likely to accelerate. As circular economy drives the macro-trend towards adopting sustainability as a proactive philosophy rather than an afterthought, game-changing technology like blockchain can be applied to enable fast-fashion circular SCM in preproduction, pro- duction, and post-production stages.

\subsection{Application of blockchain to meet the challenges of sustainability in fast fashion}

As previously discussed, a major challenge in fast fashion is the overproduction of products which directly leads to environmental and social challenges. Blockchain technology can help 
to mitigate some of these challenges by facilitating sustainable production, fair labour practices, and extending the lifespan of clothing by reducing, reusing, and recycling the resources involved.

Firstly, blockchain technology can be applied to reduce overproduction. The fast-fashion supply chain is linear (design- manufacturing-sale-disposal) (Niinimäki, 2018), causing a bullwhip effect (Lee et al., 1997). The linear structure means that only two adjacent nodes have the proximity to partially share information, so information about demand from end-customers must be distorted (mainly amplified for buffer consideration) when going up to upstream suppliers. Thus, the linear system makes for a vast amount of waste from overproduction (Agrawal et al., 2018) and transit inventory. A traditional solution has been to seek centralized information on customer demand to reduce the bullwhip effect, but this requires free communication among supply chain members (Fiala, 2005). However, this is difficult to achieve in a system fraught with "lacks", including lack of trust (Cai et al., 2010), lack of shared vision between supply chain members ( $\mathrm{Li} \&$ Lin, 2006), and lack of complete sharing of information in multi-tier supply chains (Kembro et al., 2017).

As blockchain technology can enable the creation of a decentralized, trust-free network to share the asset database peer-to-peer (Yang et al., 2018), it can furnish a supply chain with security, speed, and scale of data exchange in a distributed manner (Mylrea \& Gourisetti, 2017) among all supply chain actors (Wang et al., 2019), obviating the need to build trust. Thus, blockchain technology can enable supply chain members to collaboratively - and successfully- forecast demand (Dujak \& Sajter, 2019), minimizing the bullwhip effect in the pre-production stage. Also, blockchain technology can help to reduce fraud and errors, reduce the time, costs, and waste of fashion products in the transit process (Treiblmaier, 2018), and remove the need for double verifications (Wang et al., 2019), all of which, in turn, reduces the inventory amount of production and related packaging throughout the whole fast-fashion supply chain. Thus, the waste related to production can be much reduced in the production stage. Furthermore, the decentralized, trust-free network can share the security, speed, and scale of data including sales, stock, and transition after production in a distributed manner (Mylrea \& Gourisetti, 2017, Wang et al., 2019, Yang et al., 2018), enabling all supply chain actors to adjust their individual operations, inventory, delivery, and sales, and reorder schedules accordingly. Consequently, the whole supply chain can reduce the inventory in the whole channel in the postproduction stage. 
Secondly, blockchain technology can be applied to meet the environmental and social responsibility challenge through supplier selection and tracking supplier management. The evaluation and selection of sustainable suppliers is one of the most important decisions for achieving sustainable SCM (Ahmadi et al., 2017) in the pre-production stage. Since many fastfashion production activities have been outsourced to low-wage countries, it is critical for fastfashion companies to find reliable and trustworthy suppliers, especially those with sustainability certifications. Traditionally, fashion outsourcers each took their own approach, using a multi-criterion selection system, which may or may not include environmental, and social sustainability considerations (Govindan et al., 2013; Kahraman et al., 2003). With regard to environmental protection, the recycle/reuse/reduce option has been identified as the top criterion for supplier evaluation and selection (Luthra et al., 2017). Meanwhile, the Social Accountability 8000 (SA8000) standard certification concerns child/forced labour, health and safety, freedom of association, discrimination, disciplinary practices, working hours, remuneration, and management systems (Social Accountability International, 2014). Suppliers must meet all these basic requirements to achieve certification (Witkowska, 2016). Consequently, the supplier evaluation and selection pro- cess is complex and time consuming (Benyoucef \& Canbolat, 2007), involving a variety of actors, processes and a plethora of information.

Blockchain technology, however, can provide a better option for evaluating and selecting the right suppliers. A potential supplier must be verified before it is permitted to access the blockchain. Because of the inherent characteristics of automation (Wang et al., 2019), blockchains can be programmed to automatically trigger actions (including supplier certification) once certain conditions are met and can accelerate the flow of data between nodes (Min, 2019). Consequently, the verification can be conducted, recorded, and accessed quickly by all blockchain nodes. As a result, a blockchain-based supplier selection process will be easier, more efficient and effective to guarantee a good start of CSCM in the pre- production stage.

Since blockchains can accurately record, trace, and monitor the peer-to-peer transaction of all assets (Walport, 2016; Weber et al., 2016), the blockchain record and traceability system can support the three pillars of sustainability (Agrawal et al., 2018) by monitoring and tracing realtime occurrences in terms of environmental and social responsibilities. For example, it can 
audit the quality and safety of the use of chemicals, water, and land during fashion pro- duction (Turker \& Altuntas, 2014), besides auditing manufacturing from biological sources and technical fibers derived from non-renewable chemical resources (Scaturro, 2008). It can also detect working conditions and workers' status by collecting worksite- related data such as light, humidity, temperature and working hours (Tian, 2017; Venkatesh et al., 2020). These data can be used to analyse, evaluate/revaluate, and certify/recertify whether the suppliers have followed the ethical standards and requirements to treat their employees fairly in the production stage.

Currently, in the post-production stage, after being worn a few times, or never even sold in the first place, a vast number of fast- fashion products are treated as waste and thrown away, although they are still in a reusable condition (Niinimäki, 2018). Blockchain technology can facilitate the recycling and reusing of these fashion products in appropriate ways. Since the blockchain has verified and recorded the information of the fashion product (such as brand, model, manufacturer, components, processing technology, purchasing date) and even the consumer, the production and usage history of items can be easily tracked and authenticated. After washing and sanitizing, these second-hand items can be resold, rented, and donated to extend their active lifetime. According to Farrant et al. (2010), the purchase of 100 s-hand garments would save between 60 and 85 new garments being produced, depending on the place of reuse, exemplifying how blockchain technology application can play a significant role in CSCM in the fashion industry.

Furthermore, through blockchain verification and authentication, materials from products acknowledged to be at the end-of-life can be repurposed for other products. For example, postconsumer textile waste can be used to make other products such as bow ties, purses and even polyester hang tags. The blended fabrics can be turned into items such as decorative vases and bowls, particle boards and other sustainable composites (Lewis et al., 2017). Consequently, blockchain technology can help with minimizing the amount of textile waste that ends up in landfills and with saving on the resources used for products and production lines.

Table 3 summarizes the potential blockchain solutions for the sustainability challenges identified in the fast-fashion industry. 
Table 3. Challenges faced by the fast-fashion industry and their corresponding potential blockchain solutions

\begin{tabular}{|c|c|}
\hline Challenges & Potential blockchain solutions \\
\hline $\begin{array}{l}\text { Product economics of } \\
\text { fast-fashion products and } \\
\text { supply chain }\end{array}$ & $\begin{array}{l}\text { a. In the pre-production stage } \\
\text { - Enable the creation of a decentralized, trust-free network to share the } \\
\text { asset database peer-to-peer (Yang et al., 2018); } \\
\text { - Enable supply chain members to collaboratively - and successfully - } \\
\text { forecast demand (Dujak \& Sajter, 2019), minimizing the bullwhip effect. } \\
\text { b. In the production stage } \\
\text { - Furnish a supply chain with security, speed, and scale of data exchange } \\
\text { in a distributed manner (Mylrea and Gourisetti, 2017) among all supply } \\
\text { chain actors (Wang et al., 2019) to reduce the inventory in the whole } \\
\text { channel; } \\
\text { c. In the post-production stage } \\
\text { - Reduce fraud and errors, time, costs, and waste of fashion products in } \\
\text { the transit process (Treiblmaier, 2018) } \\
\text { - Reduce the inventory amount of production and related packaging } \\
\text { throughout the whole fast fashion supply chain. }\end{array}$ \\
\hline $\begin{array}{l}\text { Environmental and } \\
\text { social problems related } \\
\text { to sustainable supplier } \\
\text { selection in the pre- } \\
\text { production stage }\end{array}$ & $\begin{array}{l}\text { - Provide a better option for evaluating and selecting the right suppliers. } \\
\text { - Program to automatically trigger actions (including supplier } \\
\text { verification and certification) once certain conditions are met and can } \\
\text { accelerate the flow of data between nodes (Min, 2019). } \\
\text { - Supplier verification can be conducted, recorded, and accessed quickly } \\
\text { by all blockchain nodes. } \\
\text { - As a result, a blockchain-based supplier selection process will be } \\
\text { easier, more efficient, and effective in the pre-production stage. }\end{array}$ \\
\hline $\begin{array}{l}\text { Environmental and } \\
\text { social problems related } \\
\text { to suppliers in the } \\
\text { production stage }\end{array}$ & $\begin{array}{l}\text { - Blockchain record and traceability system can support the three pillars } \\
\text { of sustainability (Agrawal et al., 2018) by monitoring and tracing real-time } \\
\text { occurrences in terms of environmental and social responsibilities. } \\
\text { - Audit the quality and safety of the use of chemicals, water, and land } \\
\text { during fashion production (Turker \& Altuntas, 2014), besides auditing } \\
\text { manufacturing from biological sources and technical fibers derived from } \\
\text { nonrenewable chemical resources (Scaturro, 2008). } \\
\text { - Detect working conditions and workers' status by collecting } \\
\text { environmental data such as light, humidity, and temperature (Tian, 2017) } \\
\text { and working hours (Venkatesh et al., 2020). } \\
\text { - These data can be used to analyze, evaluate, certify, and recertify } \\
\quad \text { whether the suppliers have met the ethical standards and requirements. }\end{array}$ \\
\hline $\begin{array}{l}\text { Environmental and } \\
\text { social problems related } \\
\text { to fast fashion in the } \\
\text { post-production stage }\end{array}$ & $\begin{array}{l}\text { Blockchain technology can verify, record, track, and authenticate the } \\
\text { production and usage history of the fashion product. Products can be resold, } \\
\text { rented, and donated to extend lifetime after washing, sanitizing, and } \\
\text { quality/brand auditing. } \\
\text { acknowledged to be at the end-of-life can be reused and remanufactured into } \\
\text { other products, thus maximizing the utilization of fast-fashion products and } \\
\text { minimizing landfill waste amounts. }\end{array}$ \\
\hline
\end{tabular}

\subsection{Overall architecture of blockchain-enabled CSCM}

In order to utilize BCT for CSCM, a system architecture is developed in Fig. 1. The overall architecture was validated by two experts in BCT and SCM. A copy of this architecture and its descriptions were sent to them and their feedback was considered in order to validate and improve it. The experts play different roles in BCT adoption. One is a BCT service provider 
who has won multiple contracts to develop blockchain-based systems for businesses. The other is a senior researcher in blockchain application in supply chains and logistics and has published several relevant research papers in reputable academic journals. They both approved the general validity of the architecture. They also provided some constructive feedback at the request of the lead researcher. Based on their feedback, some revisions were made to improve the initial draft of the architecture.
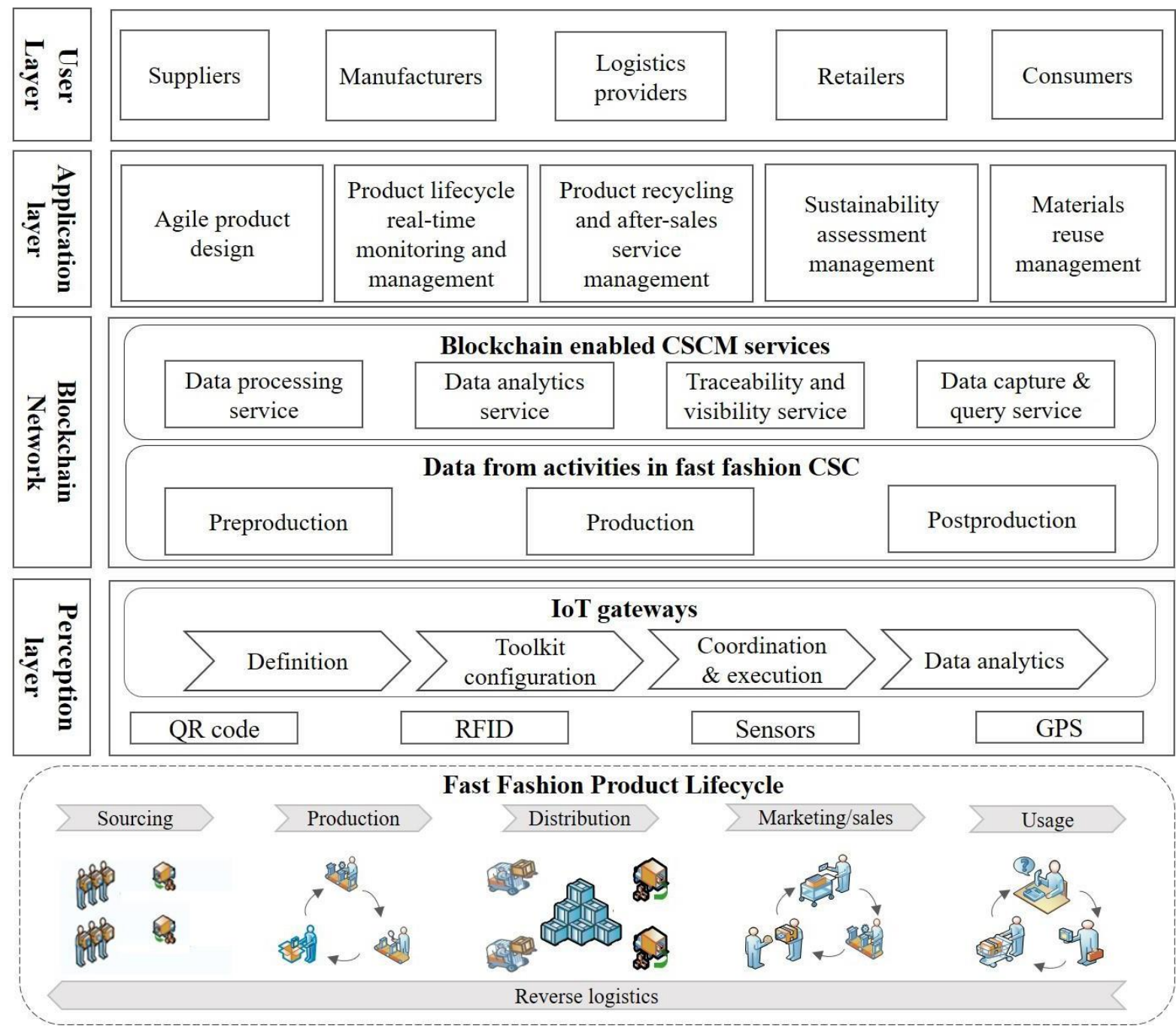

Figure 1. System architecture of blockchain-enabled CSCM

As shown in Fig. 1, the overall system architecture comprises four technical layers: the perception, blockchain network, application, and user layers. A generic fast-fashion product life cycle is presented at the bottom and the whole product life cycle is divided into sourcing, production, distribution, marketing/sales, and usage. In contrast to a linear supply chain, in which the end-of-life products go to a landfill, reverse logistics is integral in a circular supply chain to bring end-of-life products back to upstream supply-chain actors for reuse and value recovery. 
At the perception layer are the input sources of the proposed platform architecture. These are used to collect data throughout all of the product life cycle stages. At the pre-production stage, data needs to be collected on demand, forecasting, inventory, logistics, and suppliers' evaluation and selection. Data on working conditions, production processes, and environmental impacts needs to be collected in the production stage. At the post-production stage, data should include distribution, marketing, and usage processes. This data collection process is mainly achieved using IoT technologies. Various smart sensors and IoT devices, such as QR codes, RFID tags and readers, sensors, and GPS, are used to enable the deployment of IoT technologies. These smart sensors and IoT devices make up the perception network that collects data automatically (Atzori et al., 2010) from each of the product life cycle stages in a way that is easy to deploy and flexible to configure. For example, in the production stage, machine operators can tap their staff cards on a reader deployed on the machines to activate the manufacturing process. The machines then start to process components and smart sensors (like temperature sensors and electricity meters, recording the correspondence between temperature and electricity consumption) to collect data, which will be uploaded to the IoT gateways, where the data will be pre-processed.

An IoT gateway is an intermediate between the wireless sensor networks and traditional communication networks or the Internet (Zhu et al., 2010). Traditionally, as the connection between physical machinery and upper layers, an IoT gateway transforms the proto- col to go from perception to the network layer, as well as from one type of perception network to another. A gateway is used to transfer the collected data to the local and/or cloud databases and deliver the feedback to the programmable logic controller (PLC). In this paper, IoT gateways mainly control data transmissions and corresponding mechanisms that decide what types of data can be transmitted and when. These operations consist of data pre- processing, which includes data definition, toolkit configuration, coordination and execution, and data analytics. After the operations through the gateways, the data and information from the perception layer will be transmitted to the blockchain network layer.

The blockchain network layer is responsible for processing and recording the data generated from activities in all of the product life cycle stages (all the data is transmitted from IoT gateways). A blockchain-based system provides four key services to integrate data and add value to activities, namely (1) data processing, (2) data analytics, (3) traceability and visibility, 
and (4) data capture and query services. In the data processing service, data cleansing, classifying, sorting, and calculating will be conducted. For example, energy consumption can be calculated and evaluated when all the data on resources is available. Data analytics is used to extract what is useful and important from the processed data for decision making. This service is realized by various mathematical models, machine learning algorithms, and data mining technologies, which can be helpful for discovering meaningful patterns (Li et al., 2018). Traceability and visibility services allow users to visually trace product life cycle information. The processed and analysed data can be presented in statistical graphics and tables, helping users to understand the product life cycle intuitively. The data capture and query service give users easy access to data and information that they want. For example, consumers can obtain information on the certification or manufacturing process of a product. In most simple scenarios, data collected from the perception layer will be transmit- ted to the blockchain network layer and, after it is processed (the data processing service), the final hash data will be generated, along with the difficulties. All the hash values can be queried through the data capture and query service. Finally, the hash values and original object data (i.e., the data from the perception layer) will be broadcast to the blockchain network. Once they are approved by the consensus algorithm, the hash values will be stored in the blockchain network, and the original object data will be stored in the cloud storage environment servers.

The application layer, as its name suggests, provides five key applications for users, namely agile product design, product life- cycle real-time monitoring and management, product recycling and after-sales service management, sustainability assessment management, and materials reuse management. These applications run throughout the whole life cycle of fastfashion products.

Agile product design ensures that the products keep up with those of the fashion trends (Cachon and Swinney, 2011) which are beneficial for both manufacturers and customers. In a blockchain- based system, agile product design can be achieved through integrated information sharing throughout the whole product life cycle.

Product life-cycle real-time monitoring and management play important roles in collecting data and information for decision making. For example, in sourcing activities, data and information on suppliers will be recorded and managed to ensure that the latter are qualified. In production activities, the manufacturing environment and processes, in addition to the working conditions, 
can be monitored in real time to ensure the quality of products, to verify the qualification of manufacturers, and to ensure cleaner production with the aim of improving overall economic efficiency while simultaneously reducing risks and damage to the environment and people involved (Farooque et al., 2019a). In distribution activities, inventory information is monitored in real time as a basis for inventory warnings, replenishment, and control. Moreover, real-time inventory and logistics information can be used to dynamically forecast customer demand. In marketing/sales activities, product sales information is recorded as a basis for promptly developing and adjusting marketing strategies. In usage activities, recycling information can be recorded to calculate the rate of recycling and to improve recycling strategies.

Product recycling and after-sales service management are responsible for the recycling, reuse, lease, and disposal of products. Suitable recycling, reuse, and lease can not only control the wastage of potentially useful materials but also reduce the consumption of raw materials. In a blockchain-based system, manufacturers can easily identify which materials can be reused and which are to be disposed. Moreover, this application can provide reference information for environmental concerns, given that recycling and disposal are closely related to these.

Sustainability assessment management is extremely important for a circular supply chain. It involves assessing elements and factors related to the environment, economy, and society. Enterprises are assessed not only on their business qualifications, but also with regard to their responsibilities for sustainability, based on the data collected from the whole product life cycle. Sustainability assessment can be used for management of energy-saving, ecosystem quality, and waste. For example, the energy consumption can be recorded, analysed, and evaluated, and energy conversion and recycling can be calculated throughout the product life cycle. All the data on consumption and output emissions can be readily shared and integrated to evaluate the environmental performance of a product life cycle - the very essence of ecosystem quality management. Based on a blockchain system, reliable sources of data allow people to evaluate the environmental impacts of waste emissions from a product life cycle perspective (Erses Yay, 2015). The analysed results are also helpful in making decisions and strategic plans for managing waste (Khoo, 2019).

Materials reuse management is indispensable in a circular fast- fashion supply chain. This practice largely refers to arranging for textile materials from old clothing to be reused. Clothing contains a wide variety of fabrics, such as cotton, linen, nylon, wool, silk, leather, chemical 
fiber, and their blends. Different fabric materials should be classified for recycling, reuse, or disposal in a suitable way. For example, some fabrics are suitable for recycling and reprocessing, either into other clothing materials or the materials of other products (like daily necessities), while other fabrics may be more suitable for industrial use. All these classifications and identifications can be achieved through materials reuse management.

The user layer mainly consists of the parties involved in the circular supply chain: suppliers, manufacturers, logistics enterprises, retailers, and consumers. In a blockchain system, the first four parties can share information in real time to collaborate on decisions ranging from new product designs, inventory optimization, through to marketing strategies. They can also choose qualified partners and evaluate whether the environmental impacts of their supply chains and manufacturing processes follow global or national standards. Some manufacturers have selfestablished logistics systems and sales channels, making them retailers as well as logistics companies. They can connect directly both with sup- pliers upstream and customers downstream, which is much more beneficial for a circular supply chain because they can share information more effectively and respond more quickly to the market. As for consumers, they can make purchasing decisions by inquiring, through various applications, about product information, such as product certification and related environmental protection information. They can also make the best of the products they buy for reuse, lease, or recycling.

\subsection{Technical solution of blockchain-enabled CSCM}

At the fast-fashion product life cycle level, the way in which data/information flows through and connects the stages has been presented in a UML sequence diagram (Fig. 2). There are three stages: pre-production, production, and post-production. Each stage involves different types of product-related activities, applications, or services, including demand forecast, product research and development, manufacturing process control, and product recycling. Besides these, each activity can be described with a product and enterprise information. For example, for product $\mathrm{R} \& \mathrm{D}$, there is product information such as design instructions, 2D design drawings, and models. For supplier qualification certification, there is information like enterprise product output and enterprise reputation. All of the information is stored in corresponding databases. In a simple scenario, we introduce the production process in a circular supply chain to clarify the mechanism of how to integrate blockchain-based CSCM with existing applications. 


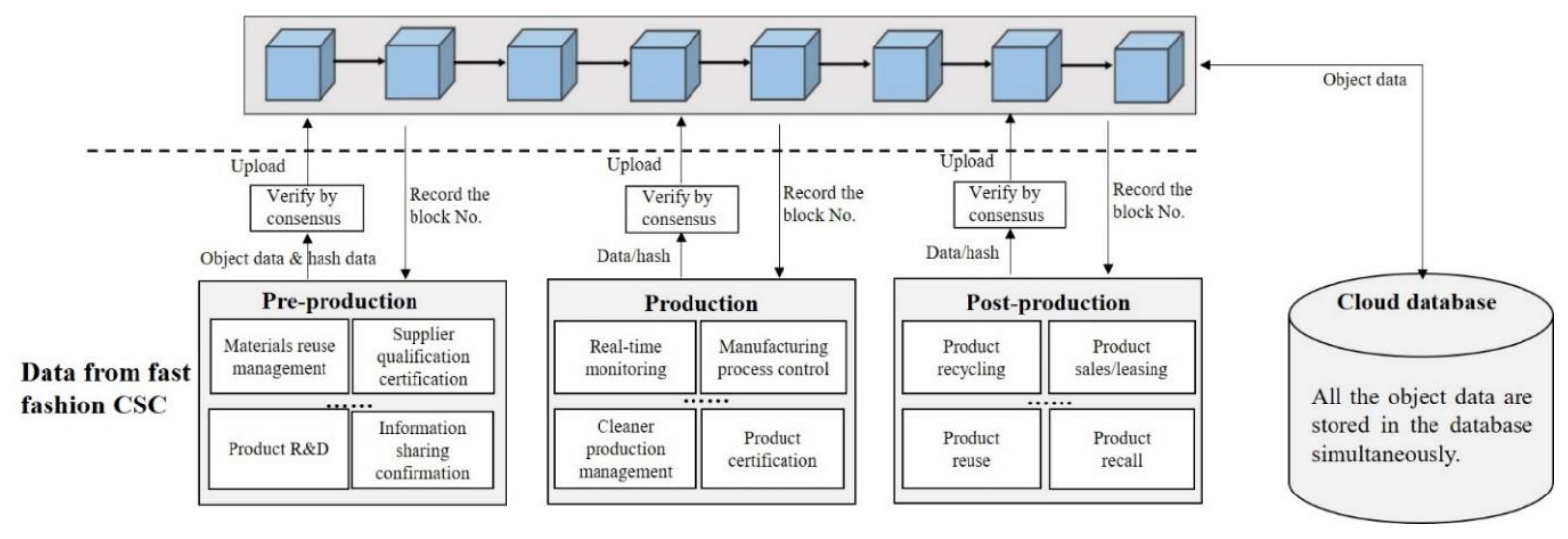

Figure 2. The data flow in circular supply chain

From a supply chain perspective, every stakeholder is involved in the circular supply chain. As shown in Fig. 3, a circular supply chain generally involves five roles, namely supplier, manufacturer, distributor, retailer, and consumer. They are linked through logistics activities. The solid line represents the forward logistics process of the products, while the dashed line represents the reverse logistics process, such as product recycling and recall. In contrast to the traditional supply chain, the circular supply chain includes reverse logistics, which is responsible for the recycling and recall of the product for reuse. The reverse logistics is the reverse process of forward logistics. In order to ensure the integrity and the trace- ability of fast-fashion products in the whole life cycle, stakeholders would upload the relevant data that is shown in the figure to the blockchain network. It not only improves the traceability of the product in the life cycle, but also provides a transparent and credible recycling environment for the product in its further usage. Therefore, it maximizes the utilization of fast-fashion products and reduces the waste of resources. The adoption of blockchain technology enables the fastfashion circular supply chain to be more sustainable and accelerates the development of a circular economy.

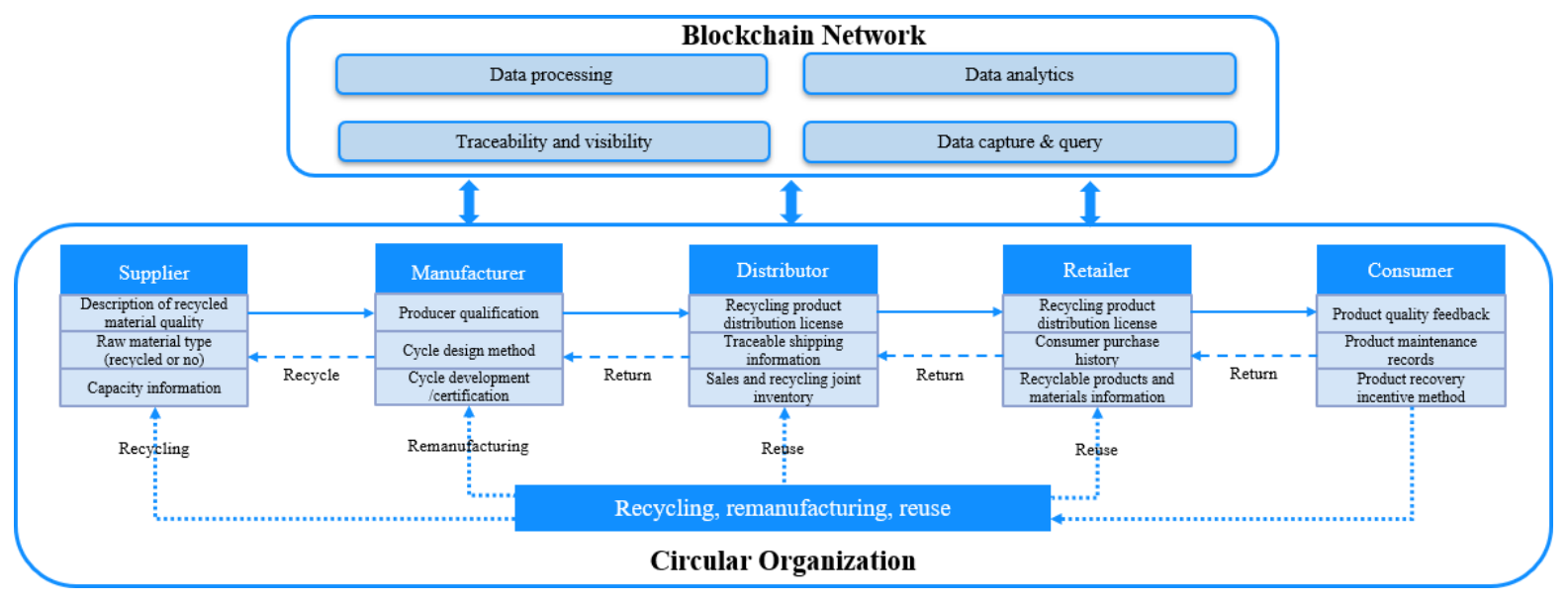


Figure 3. Stakeholders of the circular supply chain

\subsubsection{Data on and off the blockchain}

In a blockchain system, a block is created when a product sup- ply plan is generated. A block consists of a header and body. In the proposed blockchain-enabled circular supply chain management architecture, the block header contains information like a hash of the previous block, a time stamp, and version. Since the block body is of limited size, only some simple structure information is stored in it. For example, in the pre-production stage, the product name, simple product data, supplier name, product sales and demand information, product reuse information, and linkage to other data sources are stored in a block. Also, smart contracts with rules for sharing information among different supply participants are carried in the block. Simultaneously, other data and information, such as the product R \& D files, supplier qualification certification, and product demand forecast model are stored in product-related and supplier-related cloud databases. In the production stage, the block includes linkages to the cloud database. With regard to supplier linkage, it contains access to manufacturing process data, cleaner production management data, and data that is monitored in real- time. In terms of product linkage, access to product certifications, such as quality certification, are included. In the post-production stage, the recycling product linkage is stored in blocks. Again, this linkage is used to access data, in this case data on product recycling, sales/leasing, reuse, recall, and so on, all of which can ensure the sustainability of the circular supply chain.

\subsubsection{Access to the data}

Different participants in the supply chain have different authorizations and permissions in the blockchain-based CSCM platform. Suppliers need to be accredited with qualification certifications by uploading basic information about themselves if they want to take part in the production activities through the platform and access the relevant data. During the production stage, manufacturers need to upload real-time data on the manufacturing process to the cloud database. Data on their products may be uploaded later, in the pro- duction and post-production stage. Logistics enterprises provide logistics and reverse logistics service for the whole supply chain. They can access some information, for example, about inventory, when authorized by retailers. Retailers are mainly responsible for selling, so they can share the product sales information with their upstream firms and cooperative partners. Manufacturers with selfestablished logistics systems and sales channels can benefit more from a blockchain-based system because they can share their information in a more secure and efficient way. Consumers 
can access the certification information on products and suppliers to check the product quality and condition and to trace some product information. They can also be given some productrelated environmental protection information. All the information is encrypted and can- not be accessed without permission. For example, users can get data and information only through linkages that give them access to large design files in the cloud databases through the predefined application programming interface (API). It is also by permission that they access certain information, such as supplier certifications, information on working conditions, and product recycling data in order to evaluate the reliability of others and their sustainability qualifications. Notably, participants cannot tamper with data or information, either in the blockchain or in the cloud database. This is because both are linked by the hash value, and any changes will lead to an incompatibility in the proposed platform. In this way, an environment of collaborative decision-making and information sharing will be created in a blockchain-based CSCM platform, and it will provide opportunities for the stakeholders in a fast-fashion circular supply chain to respond to the market quickly.

\section{Discussion}

This research explores how BCT can enable CSCM in fast fashion. We identify three main issues relevant to CSCM in fast fashion in terms of economic, environmental, and social responsibility. We further develop a system architecture to apply BCT in CSCM in fast fashion to deal with these issues in pre-production, production, and post-production stages. Overall, our research provides valuable guidance for deploying BCT to improve circular fast-fashion supply chain management.

\subsection{Theoretical implications}

Our research is one of the first to explore the application of blockchain in CSCM, and extends the research into the fast-fashion industry. Both BCT and the circular economy are emerging hot topics with profound implications for both academia and industry (Kouhizadeh et al., 2019a, 2019b). This paper has made a valuable attempt to integrate these two topics in order to gain significant insights. BCT has incomparable and distinctive advantages such as disintermediation, transparency with pseudonymity, security, and automation (Wang et al., 2019). It can integrate with IoT and cloud technology (Sharma et al., 2017) and has been applied in a variety of areas, such as financial transactions, healthcare, logistics, and supply 
chains (Wang et al., 2019). Although some papers have studied the relationship between blockchain and the circular economy (Kouhizadeh et al., 2019a, 2019b), most of them have focused on the anti-counterfeiting and traceability aspects of blockchain technology. Certainly, there have been some operable applications and platforms based on blockchain technology in the fast-fashion industry.

A research note1 from TCBL in the European Union provided good examples. Martine Jarlgaard produced the first garments with smart labels based on Provenance, a supply chain service platform based on blockchain technology, to achieve full process traceability of her products. Her consumers can access information such as time stamps and location mapping from raw material to finished product. Babyghost teamed with VeChain, a blockchain platform that provides enterprises with blockchain as a service, to put unique IDs on the blockchain for anti-counterfeiting and the traceability of products. Brandzledger is a blockchain-based offering of cloud services tailor-made for supply chain processes. It maps out each stage of supply chains to monitor the origins and movements of separate or whole components of a product for anti-counterfeiting and traceability. Current blockchain use cases in the fast-fashion industry rarely focus on circularity of the supply chains. Indeed, there is scant research extending BCT to circular supply chain management (CSCM) in any specific industry. Given that fast fashion has caused increasing sustainability problems, such as sweatshops and the depletion of resources (Park \& Kim, 2016), this paper explores how BCT can enable CSCM in the industry by overcoming three main types of sustainability challenges. This exploration contributes to the literature of these related disciplines.

Furthermore, this paper builds a system architecture for how blockchain can enable CSCM. Moreover, the paper analyses the sustainability challenges in three stages (i.e., pre- production, pro- duction, and post-production of fast fashion) and clarifies the mechanism of integrating blockchain-based CSCM with existing applications to overcome the challenges associated with these stages. The framework proposes a blockchain platform for collaborative forecasting and planning, a blockchain-based supplier certification system, and a transparent and real-time supplier monitoring and tracing mechanism. More importantly, it suggests postproduction subsystems to resell, rent, reuse, and recycle fashion products to achieve CSCM.

\subsection{Managerial implications}


Our research offers several valuable insights to fast-fashion practitioners and suggests how to use BCT for CSCM in fast fashion. Firstly, all stakeholders need to give serious consideration to sustainability problems in the fast-fashion industry, including the vast amount of resources wasted, pollution caused by chemicals, and harm to the workers and communities. Since all the sustainability problems are related to the overproduction and shortened life cycle of fashion products, all stakeholders, including fast-fashion companies, designers, retailers, and manufacturers, can make full use of the proposed system architecture. For the system to work, how- ever, they need to share demand information, to monitor and trace the inventory in the supply chain channels, and to collaborate on forecasting, planning, and supplementing. Thus, collaboration can efficiently and effectively reduce the inventory in the production sites and transition processes, which will benefit the whole supply chain.

Secondly, the proposed framework provides a transparent plat- form for selecting, auditing, and evaluating potential suppliers based on whether they meet the sustainability requirements. By auditing the historical data, the blockchain-based framework can be used to efficiently select the right suppliers: those who are following the SA8000 standard and other codes of conduct. By monitoring and validating how suppliers perform in relation to environmental and social responsibility in real time, the system can perfect and make efficient the supplier certification system. This can support the institutional role of some governments of emerging economies in better fulfilling environmental and social responsibilities so as to apply international standards such as SA8000.

Finally, in the blockchain-enabled fast-fashion CSCM system, post-production blockchain subsystems can be built to sell/resell, reuse, rent, and recycle fast-fashion products according to their condition and quality after strict sanitizing and cleaning treatment processes. Products in nearly new condition can be resold, rented, and reused (which includes being donated to charity communities) in different markets. Some products can be recycled for further treatment. The goal is to extend the life cycle and to make full use of fast-fashion products.

\section{Conclusions}

The emerging BCT has great potential to be used for supply chain traceability and transparency. There are barriers to be overcome in a quest for a transition to a circular economy in which the reuse of materials is managed over multiple life cycles across a variety of spatially dispersed 
supply chain stakeholders. This study proposes a blockchain-based system architecture for operationalizing circular supply chain management in the fast-fashion sector, which is notorious in regard to environmental sustainability.

This study makes several original contributions. Firstly, to the best of our knowledge, it is the first piece of research to deal with the application of blockchain in the fast-fashion industry for transitioning to a circular economy. There is a great need to make fast fashion more sustainable. Therefore, this topic is significant and warrants further studies. Secondly, the blockchain-based system architecture that is developed in this research is a pioneering work, addressing the unique reuse/recycling challenges in fast fashion. Fast-fashion supply chains often involve many stakeholders across the globe, and their management demands great agility, transparency, and accuracy. The proposed blockchain-based system can manage the sustainability challenges in the fast-fashion supply chains to achieve a zero-waste circular economy. Two experts in BCT and SCM validated the proposed system architecture. Lastly but not least, managerial implications are discussed for implementing blockchain-based systems to manage and improve supply chain circularity.

This study has its limitations. The nature of the research is conceptual, given that the research on blockchain for the circular economy is still at a nascent stage. Although the validity of the proposed system architecture was endorsed by two BCT and supply chain experts, the researchers need to further develop the system for a small-scale pilot before applying it to a large-scale fast- fashion supply chain. Because a blockchain-based system requires data input from multiple stakeholders, and needs to involve a consortium of organizations, its implementation is often complicated. Future studies need to investigate implementation issues in incentives, barriers, and drivers. Finally, this research is limited to the fast-fashion sector. Future research may expand the scope to con- sider the application of BCT in other sectors.

\section{References}

Abeyratne, S.A., Monfared, R.P., 2016]. Blockchain ready manufacturing supply chain using distributed ledger. Int. J. Res. Eng. Technol. 5 (9), 1-10.

Agrawal, T.K., Sharma, A., Kumar, V., 2018]. Blockchain-based secured traceability system for textile and clothing supply chain. In: Thomassey, S., Zeng, X. (Eds.), Artificial Intelligence 
for Fashion Industry in the Big Data Era. Springer, pp. 197-208, http://dx.doi.org/10.1007/978981-13-0080-6 10.

Ahmadi, H.B., Petrudi, S.H.H., Wang, X., 2017]. Integrating sustainability into sup- plier selection with analytical hierarchy process and improved grey relational analysis: a case of telecom industry. Int. J. Adv. Manuf. Technol. 90 (9-12), 2413-2427.

Alexandris, G., Katos, V., Alexaki, S., Hatzivasilis, G., 2018. Blockchains as enablers for auditing cooperative circular economy networks. In: 2018 IEEE 23rd Inter- national Workshop on Computer Aided Modeling and Design of Communication Links and Networks (CAMAD), IEEE, pp. 1-7.

Akhter, S., 2014]. Endless misery of nimble fingers: the Rana plaza disaster. Asian J. Women. Stud. 20 (1), 137-147, http://dx.doi.org/10.1080/12259276.2014.11666176.

Apte, S., Petrovsky, N., 2016]. Will blockchain technology revolutionize excipient supply chain management? J. Excip. Food Chem. 7 (3), 910.

Atzori, L., Iera, A., Morabito, G., 2010]. The internet of things: a survey. Comput. Netw. 54 (15), 2787-2805, http://dx.doi.org/10.1016/j.comnet.2010.01.010.

Baker-Brown, D., 2017]. 'The Circular Economy': Construction \& Demolition from 'Waste to Resource Productivity'. Government Office for Science.

Batwa, A., Norrman, A., 2020]. A framework for exploring blockchain technology in supply chain management. Oper. Supply Chain Manage.: Int. J. 13 (3), 294-306, http://dx.doi.org/10.31387/oscm0420271.

Benyoucef, M., Canbolat, M., 2007]. Fuzzy AHP-based supplier selection in e- pro- curement. Int. J. Serv. Oper. Manag. 3 (2), 172-192, http://dx.doi.org/10.1504/ IJSOM.2007.012136.

Bhardwaj, V., Fairhurst, A., 2010]. Fast fashion: response to changes in the fashion industry. Int. Rev. Retail. Distrib. Consum. Res. 20 (1), 165-173, http://dx.doi. org/10.1080/09593960903498300. 
Bocken, N., Miller, K., Weissbrod, I., Holgado, M., Evans, S., July 2018]. Slowing resource loops in the circular economy: an experimentation approach in fashion retail. International Conference on Sustainable Design and Manufacturing, 164-173, http://dx.doi.org/10.1007/978-3-030-04290-5 17.

Brooks, A., 2019]. Clothing Poverty: the Hidden World of Fast Fashion and Second- Hand Clothes. Zed Books Ltd.

Cachon, G.P., Swinney, R., 2011]. The value of fast fashion: quick response, enhanced design, and strategic consumer behavior. Manage. Sci. 57 (4), 778-795.

Cai, S., Jun, M., Yang, Z., 2010]. Implementing supply chain information integration in China: the role of institutional forces and trust. J. Oper. Manag. 28 (3), 257-268, http://dx.doi.org/10.1016/j.jom.2009.11.005.

Casado-Vara, R., Prieto, J., De la Prieta, F., Corchado, J.M., 2018]. How blockchain improves the supply chain: case study alimentary supply chain. Procedia Com- put. Sci. 134, 393-398, http://dx.doi.org/10.1016/j.procs.2018.07.193.

Cole, R., Stevenson, M., Aitken, J., 2019]. Blockchain technology: implications for operations and supply chain management. Supply Chain. Manag. Int. J. 24 (4), 469-483 10.1108.SCM09-2018-0309.

Claudio, L., 2007]. Waste couture: environmental impact of the clothing industry. Environ. Health Perspect. 115 (9), A449-A454, http://dx.doi.org/10.1289/ehp. 115-a449.

Da Xu, L., Viriyasitavat, W., 2019]. Application of blockchain in collaborative Internet-ofThings services. IEEE Trans. Comput. Soc. Syst. 6 (6), 1295-1305, http://dx.doi.org/10.1109/TCSS.2019.2913165.

Debacker, W., Manshoven, S., Peters, M., Ribeiro, A., De Weerdt, Y., June 21-23 2017. Circular economy and design for change within the built environment: preparing the transition. 
In: International HISER Conference on Advances in Recycling and Management of Construction and Demolition Waste, Delft, The Netherlands.

Dobrovnik, M., Herold, D., Fürst, E., Kummer, S., 2018]. Blockchain for and in logistics: what to adopt and where to start. Logistics 2 (3), 18, http://dx.doi.org/10.3390/ logistics2030018.

Dujak, D., Sajter, D., 2019. Blockchain applications in supply chain. In: Kawa, A., Maryniak, A. (Eds.), SMART Supply Network. Springer, pp. 21-46.

Dunlap, R.E., 2012. Environmental concern. In: The Wiley- Blackwell Encyclopedia of Globalization. Wiley-Blackwell, http://dx.doi.org/10.1002/9780470670590. wbeog173.

Earley, R., Goldsworthy, K., June 17-19 2015. Designing for fast and slow circular fashion systems: exploring strategies for multiple and extended product cycles [Conference Paper]. In: PLATE: Product Lifetimes and the Environment, Not- tingham, UK https://www.plateconference.org/designing-fast-slow-circular- fashion-systems-exploringstrategies-multiple-extended-product-cycles/.

Elmessiry, M., Elmessiry, A., 2018a]. CRYPTO COPYCAT: a fashion centric blockchain framework for eliminating fashion infringement. Int. J. Mater. Textile Eng. 12 (7), 332-339, http://dx.doi.org/10.5281/zenodo.1317406.

ElMessiry, M., ElMessiry, A., 2018b. Blockchain framework for textile supply chain management. In: Chen, S., Wang, H., Zhang, L.J. (Eds.), Blockchain - ICBC 2018. Springer, pp. 213-227, http://dx.doi.org/10.1007/978-3-319-94478-4 15.

Erses Yay, A.S., 2015]. Application of Life Cycle Assessment (LCA) for municipal solid waste management: a case study of Sakarya. J. Clean. Prod. 94, 284-293, http:// dx.doi.org/10.1016/j.jclepro.2015.01.089Get.

Farooque, M., Zhang, A., Liu, Y., 2019a]. Barriers to circular food supply chains in China. Supply Chain. Manag. Int. J. 24 (5), 677-696, http://dx.doi.org/10.1108/ SCM-10-2018-0345. 
Farooque, M., Zhang, A., Thürer, M., Qu, T., Huisingh, D., 2019b]. Circular supply chain management: a definition and structured literature review. J. Clean. Prod. 228, 882-900, http://dx.doi.org/10.1016/j.jclepro.2019.04.303.

Farooque, M., Jain, V., Zhang, A., Li, Z., 2020]. Fuzzy DEMATEL analysis of barriers to Blockchain-based life cycle assessment in China. Comput. Ind. Eng. 147, 106684, http://dx.doi.org/10.1016/j.cie.2020.106684.

Farrant, Laura, Olsen, Stig Irving, Wangel, Arne, et al., 2010]. Environmental bene- fits from reusing clothes. The International Journal of Life Cycle Assessment 15 (7), 726-736 http://baosquared.com/wp-content/uploads/2017/12/Research- Environmental-Benefits-ofused-clothes-2011-Technical-U-Denmark.pdf.

Ferreira, M.A., Jabbour, C.J.C., de Sousa Jabbour, A.B.L., 2017]. Maturity levels of material cycles and waste management in a context of green supply chain management: an innovative framework and its application to Brazilian cases. J. Mater. Cycles Waste Manag. 19 (1), 516525, http://dx.doi.org/10.1007/s10163-015-0416-5.

Fiala, P., 2005. Information sharing in supply chains. Omega 33 (5), 419-423, http:// dx.doi.org/10.1016/j.omega.2004.07.006.

Francisco, K., Swanson, D., 2018]. The supply chain has no clothes: technology adop- tion of blockchain for supply chain transparency. Logistics 2 (1), 2, http://dx.doi. org/10.3390/logistics2010002.

Fu, B., Shu, Z., Liu, X., 2018. Blockchain enhanced emission trading framework in fashion apparel manufacturing industry. Sustainability $10 \quad$ (4), 1105, http://dx. doi.org/10.3390/su10041105.

Gabrielli, V., Baghi, I., Codeluppi, V., 2013]. Consumption practices of fast fashion products: a consumer-based approach. J. Fashion Market. Manage.: Int. J. 17 (2), 206-224, http://dx.doi.org/10.1108/JFMM-10-2011-0076. 
Geissdoerfer, M., Savaget, P., Bocken, N.M., Hultink, E.J., 2017]. The circular economy: a new sustainability paradigm? J. Clean. Prod. 143, 757-768, http://dx.doi.org/ 10.1016/j.jclepro.2016.12.048.

Govindan, K., Hasanagic, M., 2018]. A systematic review on drivers, barriers, and practices towards circular economy: a supply chain perspective. Int. J. Prod. Res. 56 (1-2), 278-311, http://dx.doi.org/10.1080/00207543.2017.1402141.

Govindan, K., Khodaverdi, R., Jafarian, A., 2013]. A fuzzy multi criteria approach for measuring sustainability performance of a supplier based on triple bottom line approach. J. Clean. Prod. 47, 345-354, http://dx.doi.org/10.1016/j.jclepro.2012. 04.014.

Hull, R., Batra, V., Chee, Y.-M., Chen, Y., Coblenz, M., Deshpande, P., Deutsch, A., June 2017. Blockchain: distributed event-based processing in a Data-Centric world. Proceedings of the 11th ACM International Conference on Distributed and Event- Based Systems, 2-4, http://dx.doi.org/10.1145/3093742.3097982.

Iran, S., Geiger, S.M., 2018. To wear or to own?: Influences of values on the attitudes towards and the engagement in collaborative fashion consumption. In: Heuer, M., Becker-Leifhold, C. (Eds.), Eco-Friendly and Fair. Routledge, pp. 153-162.

Jackson, T., 2009]. Prosperity without Growth: Economics for a Finite Planet. Rout- ledge.

Johnson, T., Attmann, J., 2009]. Compulsive buying in a product specific context: clothing. J. Fashion Market. Manage.: Int. J. 13 (3), 394-405, http://dx.doi.org/ $10.1108 / 13612020910974519$.

Joy, A., Sherry Jr., J.F., Venkatesh, A., Wang, J., Chan, R., 2012]. Fast fashion, sustain- ability, and the ethical appeal of luxury brands. Fash. Theory 16 (3), 273-295, http://dx.doi.org/10.2752/175174112X13340749707123.

Kahraman, C., Cebeci, U., Ulukan, Z., 2003]. Multi-criteria supplier selection using fuzzy AHP. Logist. Inf. Manag. 16 (6), 382-394, http://dx.doi.org/10.1108/09576050310503367. 
Kant, R., 2011]. Textile dyeing industry: an environmental hazard. Nat. Sci. 4 (1), 22-26, http://dx.doi.org/10.4236/ns.2012.41004.

Kembro, J., Näslund, D., Olhager, J., 2017]. Information sharing across multiple supply chain tiers: a Delphi study on antecedents. Int. J. Prod. Econ. 193, 77-86, http:// dx.doi.org/10.1016/j.ijpe.2017.06.032.

Khoo, H.H., 2019]. LCA of plastic waste recovery into recycled materials, energy and fuels in Singapore. Resour. Conserv. Recycl. 145, 67-77, http://dx.doi.org/ 10.1016/j.resconrec.2019.02.010.

Kirchherr, J., Reike, D., Hekkert, M., 2017]. Conceptualizing the circular economy: an analysis of 114 definitions. Resour. Conserv. Recycl. 127, 221-232, http://dx. doi.org/10.1016/j.resconrec.2017.09.005.

Koszewska, M., 2018]. Circular economy — Challenges for the textile and clothing industry. Autex Res. J. 18 (4), 337-347, http://dx.doi.org/10.1515/aut-2018-0023.

Kouhizadeh, M., Sarkis, J., 2018. Blockchain practices, potentials, and perspectives in greening supply chains. Sustainability 10 (10), 3652.

Kouhizadeh, M., Sarkis, J., Zhu, Q., 2019a]. At the nexus of BCT, the circular econ- omy, and product deletion. Appl. Sci. 9 (8), 1712, http://dx.doi.org/10.3390/ app9081712.

Kouhizadeh, M., Zhu, Q., Sarkis, J., 2019b]. Blockchain and the circular economy: potential tensions and critical reflections from practice. Prod. Plan. Control. 31 (11-12), 1-17, http://dx.doi.org/10.1080/09537287.2019.1695925.

Kshetri, N., 2018]. 1 Blockchain's roles in meeting key supply chain management objectives. Int. J. Inf. Manage. 39, 80-89, http://dx.doi.org/10.1016/j.ijinfomgt. 2017.12.005.

Lambert, D.M., Enz, M.G., 2017]. Issues in supply chain management: progress and potential. Ind. Mark. Manag. 62, 1-16, http://dx.doi.org/10.1016/j.indmarman. 2016.12.002. 
Lee, H.L., Padmanabhan, V., Whang, S., 1997]. Information distortion in a supply chain: the bullwhip effect. Manage. Sci. 43 (4), 546-558.

Lewis, T.L., Park, H., Netravali, A.N., Trejo, H.X., 2017]. Closing the loop: a scalable zerowaste model for apparel reuse and recycling. Int. J. Fash. Des. Technol. Educ. 10 (3), 353-362, http://dx.doi.org/10.1080/17543266.2016.1263364.

Li, S., Lin, B., 2006]. Accessing information sharing and information quality in supply chain management. Decis. Support Syst. 42 (3), 1641-1656, http://dx.doi.org/ 10.1016/j.dss.2006.02.011.

Li, Z., Wang, W.M., Liu, G., Liu, L., He, J., Huang, G.Q., 2018]. Toward open manufac- turing: a cross-enterprises knowledge and services exchange framework based on blockchain and edge computing. Ind. Manag. Data Syst. 118 (1), 303-320, http://dx.doi.org/10.1108/IMDS04-2017-0142.

Lindström, J., Hermanson, A., Blomstedt, F., Kyösti, P., 2018]. A multi-usable cloud service platform: a case study on improved development pace and efficiency. Appl. Sci. 8 (2), 316, http://dx.doi.org/10.3390/app8020316.

Liu, X.L., Wang, W.M., Guo, H., Barenji, A.V., Li, Z., Huang, G.Q., 2020]. Industrial blockchain based framework for product lifecycle management in industry 4.0. Robot. Comput. Manuf. 63, 101897, http://dx.doi.org/10.1016/j.rcim.2019. 101897.

Lu, Y., 2018]. Blockchain and the related issues: a review of current research topics. J. Manag. Anal. 5 (4), 231-255 10.1080.23270012.2018.1516523.

Lu, Y., 2019]. The blockchain: state-of-the-art and research challenges. J. Ind. Inf. Integr. 15, 80-90, http://dx.doi.org/10.1016/j.jii.2019.04.002.

Luthra, S., Govindan, K., Kannan, D., Mangla, S.K., Garg, C.P., 2017]. An integrated framework for sustainable supplier selection and evaluation in supply chains. J. Clean. Prod. 140 (3), 1686-1698, http://dx.doi.org/10.1016/j.jclepro.2016.09.078. 
MacArthur, E., 2013]. Towards the circular economy. J. Ind. Ecol. 2, 23-44.

Mangla, S.K., Luthra, S., Mishra, N., Singh, A., Rana, N.P., Dora, M., Dwivedi, Y., 2018].

Barriers to effective circular supply chain management in a developing country context. Prod.

Plan. Control. 29 (6), 551-569, http://dx.doi.org/10.1080/09537287.2018.144.9265.

Mansfield-Devine, S., 2017]. Beyond bitcoin: using blockchain technology to provide assurance in the commercial world. Comput. Fraud. Secur. 5, 14-18, http://dx. doi.org/10.1016/S1361-3723(17)30042-8, 2017.

Martinez, V., Zhao, M., Blujdea, C., Han, X., Neely, A., Albores, P., 2019]. Blockchain- driven customer order management. Int. J. Oper. Prod. Manage. 39 (6/7/8), 993-1022, http://dx.doi.org/10.1108/IJOPM-01-2019-0100.

Masi, D., Day, S., Godsell, J., 2017]. Supply chain configurations in the circular econ- omy: a systematic literature review. Sustainability 9 (9), 1602, http://dx.doi.org/ 10.3390/su9091602. Min, H., 2019]. BCT for enhancing supply chain resilience. Bus. Horiz. 62 (1), 35-45, http://dx.doi.org/10.1016/j.bushor.2018.08.021.

Monte, M.J., 2000]. Corporate factory/supplier monitoring programs and the failure of international law in regulating Indian factory conditions. Brooklyn J. Int. Law 26 (3), 1125.

Moorhouse, D., Moorhouse, D., 2017]. Sustainable design: circular economy in fashion and textiles. Des. J. 20 (sup1), S1948-S1959, http://dx.doi.org/10.1080/ 14606925.2017.1352713.

Morgan, L.R., Birtwistle, G., 2009]. An investigation of young fashion consumers' disposal habits. Int. J. Consum. Stud. 33 (2), 190-198, http://dx.doi.org/10.1111/ j.14706431.2009.00756.x.

Morlet, A., Opsomer, R., Herrmann, S., Balmond, L., Gillet, C., Fuchs, L., 2017. A New Textiles Economy: Redesigning Fashion's Future. Ellen MacArthur Foundation.

Muradian, R., Martinez-Alier, J., 2001]. Trade and the environment: from a 'South- ern' perspective. Ecol. Econ. 36 (2), 281-297, http://dx.doi.org/10.1016/S0921-8009(00)00229-9. 
Mylrea, M., Gourisetti, S.N.G., September 2017]. Blockchain: a path to grid modern- ization and cyber resiliency. In: 2017 North American Power Symposium (NAPS). IEEE, Morgantown, US, pp. 1-5, http://dx.doi.org/10.1109/NAPS.2017.8107313.

Nakamoto, S., Retrieved December 12, 2019 from 2009. Bitcoin: A Peer-to-Peer Electronic Cash System. www.bitcoin.org.

Nyman, T., Bachelor's Thesis 2019. Increased Transparency and Prevention of Unethical Actions in the Textile Industry's Supply Chain through Blockchain. Aalto University School of Business https://pdfs.semanticscholar.org/261f/ e32ee3562d1a332a6b57e839cdd799dd9062.pdf.

Niinimäki, K. (Ed.), 2018. Sustainable Fashion in a Circular Economy. Aalto Univer- sity.

Pan, S.Y., Du, M.A., Huang, I.T., Liu, I.H., Chang, E.E., Chiang, P.C., 2015]. Strategies on implementation of Waste-To-Energy (WTE) supply chain for circular economy system: a review. J. Clean. Prod. 108 (A), 409-421, http://dx.doi.org/10.1016/j. jclepro.2015.06.124.

Park, H., Kim, Y.K., 2016]. An empirical test of the triple bottom line of customer- centric sustainability: The case of fast fashion. Fash. Text. 3 (1), 25, http://dx.doi. org/10.1186/s40691016-0077-6.

Patel, D., Bothra, J., Patel, V., 2017. Blockchain exhumed. In: 2017 ISEA Asia Secu- rity and Privacy (ISEASP), IEEE, pp. 1-12, http://dx.doi.org/10.1109/iseasp.2017. 7976993.

Queiroz, M.M., Wamba, S.F., 2019]. Blockchain adoption challenges in supply chain: an empirical investigation of the main drivers in India and the USA. Int. J. Inf. Manage. 46, 7082, http://dx.doi.org/10.1016/j.ijinfomgt.2018.11.021.

Ranta, V., Aarikka-Stenroos, L., Ritala, P., Mäkinen, S.J., 2018]. Exploring institutional drivers and barriers of the circular economy: a cross-regional comparison of China, the US, and Europe. Resour. Conserv. Recycl. 135, 70-82, http://dx.doi. org/10.1016/j.resconrec.2017.08.017. 
Remy, N., Speelman, E., Swartz, S., Retrieved from 2016. Style that's sustain- able: A New Fast-fashion Formula. https://www.mckinsey.com/business- functions/sustainability/ourinsights/style-thats-sustainable-a-new-fast- fashion-formula.

Resta, B., Gaiardelli, P., Pinto, R., Dotti, S., 2016]. Enhancing environmental manage- ment in the textile sector: an organisational-life cycle assessment approach. J. Clean. Prod. 135, 620632 10.106/j.jclepro.2016.06.135.

Rosencrance, L., May 2017]. BCT Will Help the World Go Green. Bitcoin Magazine.

Rusinek, M.J., Zhang, H., Radziwill, N., 2018]. Blockchain for a traceable, circular textile supply chain: a requirements approach. Software Qual. Profess. 21 (1), 4-24.

Ryu, J.S., 2011]. Consumer attitudes and shopping intentions toward pop-up fashion stores. J. Glob. Fash. Mark. 2 (3), 139-147, http://dx.doi.org/10.1080/20932685.2011.10593092.

Saberi, S., Kouhizadeh, M., Sarkis, J., Shen, L., 2019]. BCT and its relationships to sustainable supply chain management. Int. J. Prod. Res. 57 (7), 2117-2135, http:// dx.doi.org/10.1090/00207543.2018.1533261.

Sacha, G., 2019. Blockchain and its relevance to intellectual property law in the fashion industry. Studenckie Prace Prawnicze, Administratywistyczne i Eko- nomiczne 29, 201-213, http://dx.doi.org/10.19195/1733-5779.29.14.

Sachs, J.D., 2015. The Age of Sustainable Development. Columbia University Press. Sariatli, F., 2017]. Linear economy versus circular economy: a comparative and analyzer study for optimization of economy for sustainability. Visegrad J. Bioecon. Sustain. Dev. 6 (1), 31-34, http://dx.doi.org/10.1515/vjbsd-2017-0005.

Scaturro, S., 2008]. Eco-tech fashion: rationalizing technology in sustainable fashion. Fash. Theory 12 (4), 469-488, http://dx.doi.org/10.2752/175174108X346940. 
Sharma, P.K., Chen, M.Y., Park, J.H., 2017. A software defined fog node based dis- tributed blockchain cloud architecture for IoT. IEEE Access 6, 115-124, http:// dx.doi.org/10.1109/ACCESS.2017.2757955.

Social Accountability International, 2014. SA8000®: 2014. International Standards.

Sternberg, H., Baruffaldi, G., January 2018]. Chains in chains: logic and challenges of blockchains in supply chains. In: 51st Hawaii International Conference on System Sciences, Waikoloa, USA: IEEE, pp. 3936-3943.

Taplin, I.M., 2014]. Who is to blame? A re-examination of fast fashion after the 2013 factory disaster in Bangladesh. Crit. Perspect. Int. Bus. 10 (1/2), 72-83, http://dx. doi.org/10.1108/cpoib-09-2013-0035.

Tian, F., June 2017]. A supply chain traceability system for food safety based on HACCP, blockchain and internet of things. In: 2017 International Conference on Service Systems and Service Management, Dalian, PRC: IEEE, pp. 1-6.

Tian, Z.G., Zhong, R.Y., Vatankhah, B.A., Wang, Y.T., Li, Z., Rong, Y.M., 2020]. A blockchain-based evaluation approach for customer delivery satisfaction in sus- tainable urban logistics. Int. J. Prod. Res., http://dx.doi.org/10.1080/00207543. 2020.1809733.

Todeschini, B.V., Cortimiglia, M.N., Callegaro-de-Menezes, D., Ghezzi, A., 2017]. Innovative and sustainable business models in the fashion industry: entrepreneurial drivers, opportunities, and challenges. Bus. Horiz. 60 (6), 759-770, http://dx.doi. org/10.1016/j.bushor.2017.07.003.

Treiblmaier, H., 2018]. The impact of the blockchain on the supply chain: a theory- based research framework and a call for action. Supply Chain. Manag. Int. J. 23 (6), 545-559, http://dx.doi.org/10.1108/SCM-01-2018-0029.

Tseng, M.L., Tan, R.R., Chiu, A.S., Chien, C.F., Kuo, T.C., 2018]. Circular economy meets industry 4.0: can big data drive industrial symbiosis? Resour. Conserv. Recycl. 131, 146-147, http://dx.doi.org/10.1016/j.resconrec.2017.12.028. 
Turker, D., Altuntas, C., 2014]. Sustainable supply chain management in the fast fashion industry: an analysis of corporate reports. Eur. Manag. J. 32 (5), 837-849, http://dx.doi.org/10.1016/j.emj.2014.02.001.

van Hoek, R., 2019a]. Developing a framework for considering blockchain pilots in the supply chain - lessons from early industry adopters. Supply Chain. Manag. Int. J. 25 (1), 115-121, http://dx.doi.org/10.1108/SCM-05-2019-0206.

van Hoek, R., 2019b]. Unblocking the chain - findings from an executive workshop on blockchain in the supply chain. Supply Chain. Manag. Int. J. 25 (2), 255-261, http://dx.doi.org/10.1108/SCM-11-2018-0383.

van Hoek, R., 2019c]. Exploring blockchain implementation in the supply chain: learning from pioneers and RFID research. Int. J. Oper. Prod. Manage. 39 (6/7/8), 829-859, http://dx.doi.org/10.1108/IJOPM-01-2019-002.

Vehmas, K., Raudaskoski, A., Heikkilä, P., Harlin, A., Mensonen, A., 2018]. Consumer attitudes and communication in circular fashion. J. Fashion Market. Manage.: Int. J. 22 (3), 286-300, http://dx.doi.org/10.1108/JFMM-08-2017-0079.

Venkatesh, V.G., Kang, K., Wang, B., Zhong, R.Y., Zhang, A., 2020]. System architecture for blockchain based transparency of supply chain social sustainability. Robot. Comput. Manuf. 63, 101896, http://dx.doi.org/10.1016/j.rcim.2019.101896.

Viriyasitavat, W., Da Xu, L., Bi, Z., Sapsomboon, A., 2019]. New blockchain-based architecture for service interoperations in internet of things. IEEE Trans. Comput. Soc. Syst. 6 (4), 739-748, http://dx.doi.org/10.1109/TCSS.2019.2924442.

Walport, M.J., 2016. Distributed Ledger Technology: Beyond Blockchain. UK Gov- ernment Office for Science. 
Wang, Y., Han, J.H., Beynon-Davies, P., 2019]. Understanding blockchain technology for future supply chains: a systematic literature review and research agenda. Supply Chain. Manag. Int. J. 24 (1), 62-84, http://dx.doi.org/10.1108/SCM-03-2018-0148.

Weber, I., Xu, X., Riveret, R., Governatori, G., Ponomarev, A., Mendling, J., September 2016. Untrusted business process monitoring and execution using blockchain. International Conference on Business Process Management, 329-347, Springer. Witjes, S., Lozano, R., 2016]. Towards a more circular economy: proposing a frame- work linking sustainable public procurement and sustainable business models.

Resour. Conserv. Recycl. 112, 37-44, http://dx.doi.org/10.1016/j.resconrec.2016.04.015.

Witkowska, J., 2016]. Corporate social responsibility: Selected theoretical and empirical aspects. Comp. Econ. Res. 19 (1), 27-43, http://dx.doi.org/10.1515/ cer-2016-0002.

Yang, Z., Yang, K., Lei, L., Zheng, K., Leung, V.C., 2018]. Blockchain-based decen- tralized trust management in vehicular networks. IEEE Internet Things J. 6 (2), 1495-1505, http://dx.doi.org/10.1109/JIOT.2018.2836144.

Zhang, A., Zhong, R.Y., Farooque, M., Kang, K., Venkatesh, V.G., 2020]. Blockchain- based life cycle assessment: an implementation framework and system archi- tecture. Resour. Conserv. Recycl. 152, 104512, http://dx.doi.org/10.1016/j. resconrec.2019.104512.

Zhu, Q., Qu, Y., Geng, Y., Fujita, T., 2017]. A comparison of regulatory awareness and green supply chain management practices among Chinese and Japanese manufacturers. Bus. Strategy Environ. 26 (1), 18-30, http://dx.doi.org/10.1002/ bse.1888.

Zhu, Q., Wang, R., Chen, Q., Liu, Y., Qin, W., 2010]. IoT gateway: bridging wireless sen- sor networks into internet of things. In: 2010 IEEE/IFIP International Conference on Embedded and Ubiquitous Computing, Hong Kong, PRC: IEEE, pp. 347-352, http://dx.doi.org/10.1109/EUC.2010.58. 